\title{
Topics
}

Michael Roach*

\section{Is the Highway Patrol Really Tougher on Out-of-State Drivers? An Empirical Analysis}

\begin{abstract}
Using speeding citations from the North Carolina State Highway Patrol, this paper examines whether out-of-state drivers face different enforcement standards than in-state drivers. Discrimination effects are identified by assuming exogenous differences in license plate design affect troopers' abilities to identify out-of-state drivers. The pattern of citations for difficult to identify out-of-state drivers is significantly different from (indeed, stricter than) the pattern for more easily identifiable out-of-state drivers. I take this as evidence of troopers attempting to apply different enforcement standards to out-of-state drivers. One explanation is troopers attempting to deter in-state speeders whose behavior may be more sensitive to enforcement.
\end{abstract}

Keywords: discrimination, law enforcement, deterrence

\section{Introduction}

The profiling of particular demographic groups has been a topic of interest in a number of academic disciplines as well as in the general public discourse. It has most often been examined in the context of race, but the general issue is whether individuals with a particular observable characteristic receive a different type or level of treatment-based simply on the presence of that characteristic. Data on traffic citations have been used in several studies attempting to measure discrimination because the decisions surrounding these citations depend in a substantial way on the discretion of the enforcing agent. This paper uses that type of data to test whether state speeding enforcement authorities engage in any kind of preference-based discrimination against a very particular demographic group: out-of-state drivers.

*Corresponding author: Michael Roach, Department of Economics and Finance, Middle Tennessee State University, Murfreesboro, TN 37132, USA, E-mail: michael.roach@mtsu.edu 
Anecdotal evidence from various jurisdictions indicates that drivers from other jurisdictions may indeed be treated differently. For instance, in Helmetta, NJ, only 2 out of 222 speeding tickets issued between September 2011 and March 2013 went to Helmetta residents (Amaral 2013), and in Iowa, a recent study has shown that since $2008,86 \%$ of warnings and citations issued by two State Patrol interdiction teams have gone to out-of-state drivers (Rood 2013). While these statistics are descriptive in nature and do not firmly establish any kind of causal relationship, they certainly raise the possibility of differential treatment of drivers along these lines. There are several reasons why this is a question of interest. First of all, preference-based discrimination can certainly constitute an inefficient use of resources. It potentially focuses too many law enforcement resources on a particular demographic group at the expense of focusing them on another. Given the value of law enforcement and public safety resources, any potential improvements in their allocation should certainly be considered. In addition to efficiency concerns, there are equity issues. Discrimination against a particular group potentially undermines the notions of justice and fairness. Public agencies engaging in this type of activity risk undermining public confidence in them, which brings with it a social cost (citizens might be less willing to cooperate, etc.). Thirdly, unlike racial profiling, the motivation for which can be personal and complicated, the profiling of out-of-state drivers may be based on the institutional incentives of the enforcement agents. If these incentives lead to discriminatory activity in a way that is inefficient, it may be possible to reduce or eliminate the power of these incentives and replace them with incentives more aligned with the agency's overall objective. An examination of plausible explanations for any findings of discrimination, as is done here, would be a key step in the consideration of any policy changes.

As in other analyses of discrimination, the specifics of the paper stem from the basic question of whether the standards with which laws (in this case, speeding laws) are enforced are in the same way across demographic groups. Consistent standards of enforcement across groups would certainly be a reasonable goal for the enforcement agency if it is trying to maximize public safety on the highways, and indeed the North Carolina State Highway Patrol (NCSHP) states that this is their enforcement strategy. ${ }^{1}$ Using speeding citations issued by

1 The public information officer of the NCSHP has stated that troopers issue citations for "clearcut and substantial" violations regardless of whether the driver is from North Carolina or not. This implies that a consistent standard is in fact the objective. It is certainly reasonable to ask whether this is the appropriate objective. This paper does not seek to judge which objective is more appropriate; rather, it attempts to demonstrate that out-of-state drivers are indeed treated differently than in-state drivers as it relates to being stopped and cited for speeding. 
the NCSHP between January and August 2000, this paper empirically examines whether the NCSHP is attempting to apply consistent standards to in-state and out-of-state drivers. It should be noted that consistent enforcement standards do not necessarily equate to similar outcomes across groups. I would only expect similar outcomes to occur if the underlying distribution of driving activity was the same for each group, and I do not assume that. Thus, differences in speeding citations between in-state and out-of-state drivers can occur because of differences in the underlying distributions of speeding activity (the "at-risk population" or "at-risk distribution") or because of the decision to stop a given motorist is influenced by the state from which the car comes. If something other than differences in the underlying distribution explains the differences in enforcement, this could be due to preference-based discrimination against a particular group (Knowles, Persico, and Todd 2001).

The empirical strategy of this paper is to use data on speeding citations to establish the average patterns of speeding enforcement for in-state and out-ofstate drivers, respectively. After establishing these baselines, ${ }^{2}$ I test whether the ease with which a trooper can identify a driver as being from another state affects speeding enforcement outcomes. I do this using a novel identification strategy based on variation in how similar the plates from various states are to North Carolina's. I find that, compared to out-of-state drivers who are easy to identify (because of similar-looking license plates), out-of-state drivers who are more difficult to identify face a stricter pattern of enforcement. Given that this effect is statistically significant and robust to specification, I take this as evidence that troopers are indeed attempting to apply different standards of enforcement to out-of-state drivers (with varying degrees of success). While other papers in the literature have focused on local fiscal and political conditions as theoretical explanations for differences in enforcement intensity, the results of this analysis suggest an attempt to deter in-state drivers from speeding (an effect that is relatively favorable for out-of-state motorists, which runs counter to previous findings in the literature) may also be important.

The rest of this paper is organized as follows: Section 2 reviews the relevant existing literature, Section 3 discusses the theoretical framework of the analysis, Section 4 describes the data, Section 5 describes the identification strategy, Section 6 discusses the empirical specifications and results, and Section 7 concludes.

2 I take these baseline differences in outcomes as given. The underlying cause of these baseline differences (whether it is solely a function of different distributions of speeding activity or it is influenced by other factors) does not matter for the sake of identification. 


\section{Literature review}

Previous studies have used data on traffic stops for a number of purposes related to the consistency of enforcement standards, with many focusing on the practice of racial profiling. Indeed, the data I utilize were originally compiled for a study on racial profiling in North Carolina. The results of this study indicate that while some racial disparities do exist, they can be explained in part by trooper deployment decisions and differences in driver behavior across race (Smith et al. 2003). The study found no conclusive proof of profiling practices (although there were some individual officers who were outliers and who, consequently, might require additional scrutiny). Typically, since the organizations and researchers performing the study have information on the distribution of citations and stops by race, the key empirical hurdle in all of these studies is measuring or estimating the racial composition and distribution within the population at risk of receiving a citation. Without that, they cannot draw any sort of inference about the possible presence of preference-based discrimination. In other words, uncertainty about the population at risk of being cited creates a benchmarking issue, where it is difficult to find an appropriate standard to which the outcomes of a particular group should be compared.

One strategy that has been used to investigate preference-based discrimination in traffic enforcement involves examining patterns in vehicle searches conditional on being stopped. Differences in patterns and the relative success of these searches can be compared across demographic groups. Knowles, Persico, and Todd (2001) use this approach and find little evidence of racial prejudice. Anwar and Fang (2006) show that officers of different races are not monolithic in their vehicle search behavior, but their test does not reject the hypothesis that officers do not exhibit racial prejudice. Other studies (Hernandez-Murillo and Knowles 2004; Close and Mason 2007; Antonovics and Knight 2009) have extended this line of research and have found evidence of racial prejudice as it relates to conducting searches.

Another study on racial profiling, Grogger and Ridgeway (2005), deals with the problem of measuring the underlying at-risk population by using a "veil of darkness" assumption. This assumption asserts that at night, officers cannot determine the race of a driver until after that person has been stopped. Using exogenous changes in the amount of daylight at a given time of day, they compare the racial composition of the group stopped in the light to the group stopped in the dark, finding little evidence of racial profiling in traffic stops. An advantage of this approach is that it requires only measuring relative changes in enforcement patterns, a feature that makes it conceptually similar to the 
analysis presented here (though this paper uses a new source of identifying variation, differences in license plate designs, rather than variation in daylight).

Other papers have used traffic citation data to examine inconsistency in enforcement standards in the context of officer incentives. Garrett and Wagner (2009) find that traffic tickets are countercyclical to some extent, meaning that in times of low tax revenues, enforcement increases. Makowsky and Stratmann (2009) consider this issue as it relates to drivers from districts other than where the citation was issued (they also account for the subset of these out-of-district drivers that are from out-of-state), offering two separate explanations. The first explanation, similar to the one in Garrett and Wagner (2009), is that officers are more likely to cite out-of-district drivers than in-district drivers because it improves local revenues without upsetting voters in their district (the "political economy" explanation). The second explanation is that these out-of-district motorists are less likely than in-district drivers to contest the ticket in court, and since a driver contesting a ticket requires an officer to be present in court (which is costly to the officer), officers choose to cite a disproportionate number of out-of-district motorists (the "opportunity cost" explanation). They find evidence supporting both of these explanations. It is worth noting that these studies focus largely on the incentives of officers associated with a local municipality, and that municipality may depend in part on revenues generated from speeding citations. The NCSHP is a state agency, and thus its agents might be less sensitive to local fiscal conditions. Thus, the "political economy" explanation might be less important in the context of this paper. These differences in officer incentives certainly matter from the perspective of comparing the results of this analysis to previous studies and understanding the different theoretical explanations that help explain these results (such as the possibility of attempting to deter in-state drivers from speeding, which this paper considers).

\section{Theoretical framework}

Since this paper tests for the possibility of preference-based discrimination in speeding enforcement, it is important to be clear about the theoretical explanations for why such discrimination may exist. The first two possibilities are the central hypotheses tested in Makowsky and Stratmann (2009): the political economy explanation and the opportunity cost explanation. Both of these effects would lead to out-of-state drivers being subject to stricter enforcement of laws. A third possible explanation is a deterrence effect, and it is also referred to in Makowsky and Stratmann (2009). The basic idea is that the speeding behavior of residents is likely to be more sensitive to enforcement than that of out-of-state 
drivers, and since speeding citations are more effective against residents, one would expect stricter enforcement against them. The practical impact is even more pronounced if one assumes that these residents are the motorists spending more time on a state's roads. Taken together, these theoretical explanations do not yield a clear prediction about whether out-of-state drivers should face stricter or more lenient enforcement. I consider the plausibility of these explanations in light of the empirical findings in Section 6.

The dimension upon which I am testing for possible discrimination is also a key theoretical feature. Makowsky and Stratmann (2009), for instance, focus on the following questions: given that a motorist has been stopped, how likely is an officer to issue a citation, how large of a fine is expected, and do these expectations change for out-of-district (or out-of-state) drivers? In that way, it is similar to empirical examinations of vehicle searches, which take the decision to stop a vehicle as given and the decision to conduct a search as the dimension upon which preference-based discrimination occurs. As Anwar and Fang (2006) note, discrimination can occur in the stop decision as well (though they ignore it and only focus on the additional discrimination in the search decision). The analysis presented here focuses on that other margin of discrimination: it considers whether the set of out-of-state drivers stopped for speeding differs in a fundamental way from the set of in-state drivers stopped for the same thing.

To be clear about why this is so, consider a trooper's decision about whether to issue a speeding citation (the citation, rather than the stop, is the unit of observation in this analysis), which I assume unfolds in three sequential steps:

1. A trooper observes a motorist who is eligible to be cited for speeding. At this point, the trooper is certain of the value of the motorist's speed (and thus, by how much that speed exceeds the speed limit) but is uncertain of whether the driver is from North Carolina or another state. The license plate design gives an informative, but noisy signal, about where the driver lives (since it might be difficulty for the trooper to see the plate with perfect clarity). Taking that signal into account, the trooper updates beliefs about the likelihood that the driver is from North Carolina. The trooper then makes the decision to either stop the motorist or not.

2. If the trooper chooses to stop the motorist, the trooper learns with certainty all the characteristics of the motorist. This includes whether the motorist is from North Carolina or another state.

3. The trooper decides whether to issue the ticket at the observed speed. ${ }^{3}$

3 Another possible issue involves troopers citing a motorist at a lower speed than was actually observed. A trooper might be more likely to do this for an in-state driver if it lowers the likelihood that the motorist contests the ticket. This does not affect the identification strategy 
The key here is that there is uncertainty about whether the driver is from out-ofstate when the stopping decision is made. If troopers are attempting to apply different enforcement standards to out-of-state drivers, then I predict different patterns of issued citations for easy to identify out-of-state drivers as compared to difficult to identify out-of-state drivers. If such a factor leads to conditionally lower cited speeds, it can be interpreted as leading to stricter enforcement standards (since, on average, less serious violations are receiving citations).

\section{Data}

The main data used in this analysis center on citations issued by the NCSHP. These data, originally compiled for the North Carolina Highway Traffic Study, include citations recorded by the NCSHP from January 2000 through August 2000. ${ }^{4}$ The key outcome variable I consider is overspeed (which is the difference between the charged speed and the speed limit), an outcome that can only be calculated for speeding citations. Because of this fact, I restrict attention to citations involving the three main speeding charge codes in the data. ${ }^{5}$ The data also include the time and location of the citation, the charged speed, the speed limit, the race of the driver, and the state who issued the driver's license. I have supplemented the Highway Patrol data with information on weather conditions compiled by the National Climactic Data Center. For each county, this includes the daily records on precipitation and snow accumulation for a collection station within that county (or, in the case of counties that have no stations within them, an adjacent county).

In order to arrive at a subset of data that is common to all the specifications I run, I eliminate observations for which I do not observe the state that issued a

so long as, within the set of out-of-state drivers cited, reductions in the cited speed are uncorrelated with an out-of-state driver's license plate design. Since uncertainty about whether the driver is from out-of-state or not has been resolved by the time the citation is issued, I make this assumption, allowing me to ignore this issue.

4 Since the data used in this study are limited to citations, it does not include instances where a motorist was stopped and not issued a citation. Thus, I cannot make any definitive statements about discrimination as it relates to decisions made after the stop is made (e.g. questions about the likelihood of issuing a citation to an out-of-state driver as opposed to an in-state driver given they are stopped), such as is done in Makowsky and Stratmann (2009).

5 The first two charges are simply speeding charges (with one charge usually used for lower values of overspeed, the other for higher values), the third is for speeding in a work zone. Together these account for over $99 \%$ of the charges in the data for which overspeed can be calculated. 
driver's license, observations for which I cannot calculate relevant weather and time of day variables, and observations where the charged speed exceeds the speed limit by 50 or more miles per hour. ${ }^{6}$ Also, since the paper focuses on the discretion exercised by officers in determining who to stop for speeding, to the extent possible, I have tried to remove observations for which factors other than speed could be the motivation for a stop. Thus, for comparability purposes, I exclude observations for which the citation includes charges in addition to speeding, since those additional violations certainly could affect stopping decisions. With these restrictions, the subset of data on which I conduct all statistical analysis includes 143,583 individual citations.

With regard to license plates, I have inspected the designs of the license plates in use by various states and provinces during the first 8 months of $2000 .^{7}$ I have categorized each plate as either similar to North Carolina's (similar plate $=1$ ) or not (similar plate $=0$ ). The criteria used to make this determination are given in Table 1. As a robustness check, in some specifications I separately identify states with license plates that have a solid, non-white background color. ${ }^{8}$ This is a subset of the plates that are considered not similar to North Carolina's that can be considered even more clearly dissimilar. As another robustness check, I consider whether the state from which an out-of-state driver comes requires both front and rear plates, since this fact could also help officers

Table 1: Description of categories of license plate similarity

\begin{tabular}{ll}
\hline Description \\
\hline Similar plate $=1$ & $\begin{array}{l}\text { Primarily white background with blue coloring somewhere on plate, } \\
\text { background images must be blue or grey, plate numbers/letters must } \\
\text { be black or blue, other (identifying state or motto, for instance) can } \\
\text { include red coloring. }\end{array}$ \\
Similar plate $=0$ & $\begin{array}{l}\text { Background that is either multi-colored or non-white, letters that are } \\
\text { neither black or blue, lack of blue coloring anywhere on plate, and/or } \\
\text { use of other colors (besides blue and grey) in background images. }\end{array}$ \\
\hline
\end{tabular}

6 These instances, while quite rare in the data (this restriction reduced the sample size by 42 observations, which is $0.029 \%$ of the sample size), often seem to be miscoded in some way.

7 This was done using the website http://www.15q.net, which contains information on North American license plates. It should be noted that states do periodically change their plate designs (though most of these changes are relatively minor). North Carolina's basic design has been unchanged since 1983.

8 Six states that fall into this category: Colorado, Connecticut, Delaware, Michigan, New Mexico, and Vermont. 
distinguish between North Carolina and out-of-state drivers. Information on this front plate requirement comes from Walden et al. (2012). ${ }^{9}$

An important note is that I do not directly observe the license plate of the individual cited. Rather, I observe the state that issued the driver's license and assume that the state issuing the driver's license is the state that issued the license plate. While having to make this assumption is a potential source of measurement error, it should be noted that in general, this type of measurement error should bias the results toward zero, so the significance of the results is in spite of this issue. ${ }^{10}$ Table 2 identifies which states were designated as having a similar license plate design to North Carolina's and the frequency with which those states were observed in the data. Images of the license plates that have been categorized as similar to North Carolina's and those categorized as not similar to North Carolina's can be found in Appendices 1 and 2, respectively. North Carolina's license plate is the first one shown in Appendix 1.

Table 2: License plate similarity by state

\begin{tabular}{lrrrr}
\hline Similar plate $=\mathbf{1}$ & & & Similar plate $=\mathbf{0}$ \\
\cline { 1 - 2 } State/Province & obs. & & State/Province & Obs. \\
\hline BC & 5 & & AK & 13 \\
CA & 283 & & AL & 154 \\
IA & 17 & & AR & 33 \\
IL & 187 & & AZ & 52 \\
LA & 100 & & CO & 45 \\
MN & 22 & & CT & 127 \\
NV & 18 & & DC & 81 \\
ON & 19 & & DE & 51 \\
RI & 25 & & FL & 1,063 \\
TX & 323 & & GA & 1,203 \\
VA & 1,709 & HI & 16 \\
WA & 36 & ID & 4 \\
& & IN & 92 \\
& & KS & 24 \\
\hline
\end{tabular}

9 Thirty-one states and Washington, D.C. require front license plates. North Carolina is one of the 19 states that does not require one.

10 This assumes that any measurement error of this nature is random and thus uncorrelated with the independent variables used in the regressions. 
Table 2: (Continued)

\begin{tabular}{|c|c|c|c|}
\hline \multicolumn{2}{|c|}{ Similar plate $=1$} & \multicolumn{2}{|c|}{ Similar plate $=0$} \\
\hline State/Province & obs. & State/Province & Obs. \\
\hline & & KY & 112 \\
\hline & & MA & 121 \\
\hline & & MD & 659 \\
\hline & & $\mathrm{ME}$ & 21 \\
\hline & & MI & 140 \\
\hline & & MO & 46 \\
\hline & & MS & 66 \\
\hline & & MT & 5 \\
\hline & & ND & 2 \\
\hline & & $\mathrm{NE}$ & 11 \\
\hline & & $\mathrm{NH}$ & 31 \\
\hline & & NJ & 348 \\
\hline & & NM & 26 \\
\hline & & NY & 723 \\
\hline & & $\mathrm{OH}$ & 291 \\
\hline & & OK & 38 \\
\hline & & $\mathrm{OR}$ & 16 \\
\hline & & PA & 433 \\
\hline & & SC & 1,420 \\
\hline & & SD & 11 \\
\hline & & TN & 513 \\
\hline & & UT & 17 \\
\hline & & VT & 11 \\
\hline & & WI & 31 \\
\hline & & WV & 149 \\
\hline & & WY & 7 \\
\hline
\end{tabular}

Notes: Statistics computed from data compiled for North Carolina Highway Traffic Study. Sample is restricted to include only citations where speeding was the sole charge, citations where the charged speed exceeds the speed limit by no more than 50 miles per hour, and observations where the relevant weather and time of day variables used in the analysis were observed. The variable similar plate indicates that the driver's license was issued in a state which has a license plate design similar to that of North Carolina (precise definitions of "similar" are given in Table 1).

\section{Identification strategy}

The major empirical issue that this paper (and other papers on discrimination) must confront is that econometricians do not directly observe the population of 
interest: the subset of the overall population that is violating a given law (the "at-risk population"). What is observed (citations) represents only a subset of that offending population (the subset of the population that was actually caught breaking the law and cited for it). Since that is the only subset of offenders I observe, I must use an identification strategy based on relative changes in the observed patterns of citations rather than one based on an estimate of the at-risk distribution. The first step in this identification strategy involves assuming that the at-risk distribution remains stable over some relevant horizon. The second step involves testing whether some exogenous change in circumstances (that should not affect outcomes in the absence of any kind of discrimination) affects the likelihood that members of some subset of the at-risk population receive a citation. Thus, there is an identified benchmark against which outcomes can be compared.

Differences in license plate design across states provide this identifying variation when two assumptions are made. The first is that, conditional on other observable characteristics, how similar a state's license plate colors and designs are to the North Carolina's plates is uncorrelated with the unobserved propensity of a given out-of-state driver to break speeding laws. This implies that the expected patterns of citations (conditional on observable characteristics) would be similar across groups of out-of-state drivers that differ only by the design of their license plates. ${ }^{11}$ The second assumption is that an average trooper's likelihood of being able to distinguish an out-of-state license plate from a North Carolina plate is higher when that license plate design is not similar to North Carolina's (i.e. similar plate $=0$ ).

Having made these two assumptions, I use linear regression models to test whether this exogenous difference in license plate similarity affects the observed values of overspeed. If troopers are attempting to use different standards of enforcement for out-of-state drivers (and are doing so with some degree of success, but not complete success), I expect the license plate design variables

11 Darkness might be one factor that could potentially change discrimination dynamics in terms of how effectively an enforcement agent can distinguish between groups. However, this is not something that I am able to make any sort of hypothesis about. The problem lies in the fact that I cannot make a palatable assumption about whether darkness makes different looking plates more or less distinguishable for plates that resemble North Carolina plates. Some might believe that darkness makes all plates indistinguishable from one another. Others might believe that these plates, which have a light shining on them when headlights are turned on, become more distinguishable because of that light. Since I cannot make a reasonable hypothesis about the ability to distinguish between different types of plates in the daytime as opposed to the night, empirical analysis would neither support nor refute claims of discrimination. 
to be statistically significant, with negative coefficients interpreted as contributing to more intense (stricter) enforcement.

\section{Empirical specifications and results}

In order to discuss variation in enforcement across groups, it is first important to understand in general terms what the enforcement outcomes look like. Table 3 presents descriptive statistics on the speeding violations and associated characteristics for the entire data set and the subset of out-of-state drivers, respectively. $26 \%$ of out-of-state drivers come from states with plates similar to North Carolina's, $4 \%$ come from states with solid background color plates, 50\% come from states requiring front license plates, and 45\% are from a state that borders North Carolina (these bordering states are Virginia, Tennessee, Georgia, and South Carolina).

Table 3: Descriptive statistics

\begin{tabular}{lrrrrrr}
\hline Variable & \multicolumn{2}{c}{ All citations } & & \multicolumn{2}{c}{ Out-of-state citations } \\
\cline { 2 - 3 } \cline { 6 - 7 } & Observations & Mean & & Observations & Mean \\
\hline Speed limit & 143,583 & 55.986 & & 37,333 & 58.581 \\
Interstate & 143,583 & 0.249 & & 37,333 & 0.436 \\
Overspeed & 143,583 & 16.724 & & 37,333 & 16.451 \\
Weekend & 143,583 & 0.348 & & 37,333 & 0.392 \\
Out-of-state driver & 143,583 & 0.260 & & 37,333 & 1.000 \\
Driver from bordering state & 143,583 & 0.117 & & 37,333 & 0.450 \\
Driver from bordering county & 143,583 & 0.042 & & 37,333 & 0.162 \\
Snow & 143,583 & 0.003 & & 37,333 & 0.004 \\
Rain & 143,583 & 0.280 & & 37,333 & 0.285 \\
Low speed charge & 143,583 & 0.612 & & 37,333 & 0.690 \\
High speed charge & 143,583 & 0.378 & & 37,333 & 0.293 \\
Work zone speeding charge & 143,583 & 0.010 & & 37,333 & 0.017 \\
Similar plate & 143,583 & 0.807 & & 37,333 & 0.259 \\
Plate with solid color background & 143,583 & 0.010 & & 37,333 & 0.039 \\
Front plate required & 143,583 & 0.130 & & 37,333 & 0.501 \\
White driver & 143,583 & 0.705 & & 37,333 & 0.714 \\
Black driver & 143,583 & 0.229 & & 37,333 & 0.220 \\
\hline
\end{tabular}

Notes: Statistics computed from data compiled for North Carolina Highway Traffic Study. Sample is restricted to include only citations where speeding was the sole charge, citations where the charged speed exceeds the speed limit by no more than 50 miles per hour, and observations where the relevant weather and time of day variables used in the analysis were observed. "Outof-state citations" is the subset of this sample where the license of the driver was issued by a state other than North Carolina. An observation is a speeding citation. The variable overspeed is the difference between the charged speed and the speed limit on a given citation. 
Table 4: Summary of overspeed distributions: North Carolina drivers, out-of-state drivers with similar plates, and out-of-state drivers without similar plates

\begin{tabular}{|c|c|c|c|}
\hline & & & Overspeed percentiles \\
\hline Percentile & NC drivers & $\begin{array}{r}\text { Out-of-state with } \\
\text { similar plates }\end{array}$ & $\begin{array}{r}\text { Out-of-state without } \\
\text { similar plates }\end{array}$ \\
\hline 5 & 12 & 10 & 10 \\
\hline 10 & 13 & 12 & 11 \\
\hline 15 & 13 & 13 & 13 \\
\hline 20 & 14 & 14 & 14 \\
\hline 25 & 15 & 15 & 15 \\
\hline 30 & 15 & 15 & 15 \\
\hline 35 & 15 & 15 & 15 \\
\hline 40 & 15 & 15 & 15 \\
\hline 45 & 15 & 15 & 15 \\
\hline 50 & 15 & 15 & 15 \\
\hline 55 & 15 & 15 & 15 \\
\hline 60 & 16 & 15 & 15 \\
\hline 65 & 17 & 15 & 15 \\
\hline 70 & 18 & 15 & 15 \\
\hline 75 & 19 & 17 & 18 \\
\hline 80 & 20 & 19 & 20 \\
\hline 85 & 21 & 21 & 22 \\
\hline 90 & 23 & 23 & 24 \\
\hline 95 & 25 & 26 & 26 \\
\hline
\end{tabular}

Notes: Statistics computed from data compiled for North Carolina Highway Traffic Study. Sample is restricted to include only citations where speeding was the sole charge, citations where the charged speed exceeds the speed limit by no more than 50 miles per hour, and observations where the relevant weather and time of day variables used in the analysis were observed. "Out-of-state citations" is the subset of this sample where the license of the driver was issued by a state other than North Carolina. An observation is a speeding citation. The variable overspeed is the difference between the charged speed limit on a given citation.

Table 4 summarizes the distributions of overspeed for three groups of drivers relevant to the analysis: North Carolina drivers, out-of-state drivers with similarlooking license plates, and out-of-state drivers without similar-looking license plates. While each group has a median and mode overspeed of 15 , compared to both groups of out-of-state drivers, North Carolina drivers are less likely to be cited at very low overspeed (a lower percentage of their citations, compared to the out-of-state groups, have an overspeed below 13), but they are much more likely to be cited for an overspeed between 16 and 20. It is also worth noting that, for the 15th percentile and above, the overspeed values for the out-of-state drivers with non-similar plates are at least as high as those for the out-of-state 
with similar plates, with strictly higher values for a number of percentiles at the upper end of the distribution.

\subsection{Main results}

Since citations for out-of-state drivers occur under different conditions than instate drivers (a higher percentage are on weekends and interstate highways, for instance), I use a regression analysis to account for these factors. There are two main explanatory variables of interest in these regressions: the indicator for whether the motorist is from a state other than North Carolina (out-of-state driver) and the interaction between out-of-state driver and similar plate. The coefficient on out-of-state driver is the average differential in overspeed between in-state and out-of-state drivers. It provides a context for the magnitude of the coefficient on the interaction term, which gives an estimate of the extent to which officers are attempting to apply different standards to out-ofstate drivers. With this in mind, the regression models have the following basic form:

$$
\begin{aligned}
& \text { overspeed }_{i j c t}=\beta_{0}+\left(\text { out-of-state driver } r_{i j t}\right) \beta_{1}+(\text { out-of-state driver } \text { ouct }) \\
& \text { * }\left(\text { similar plate }_{j}\right) \beta_{2}+\left(\text { time dummies }_{t}\right) \beta_{3}+\left(\text { weather }_{c t}\right) \beta_{4} \\
& +Z_{i j c t} \beta_{5}+\varepsilon_{i j c t}
\end{aligned}
$$

Here, as for the rest of the paper, " $i$ ” indexes the individual driver, " $j$ ” indexes the state where the driver is registered, " $c$ " indexes the county where the citation is issued, and " $t$ " indexes the time (hour of a particular day) which the citation is issued), $Z_{i j c t}$ is the set of observable covariates. The coefficients of interest are $\beta_{1}$ and $\beta_{2}$. To account for possible correlation of errors for drivers from a given state, I have clustered the standard errors at the state level (here, and in all regression models in this paper).

For the sake of robustness, several specifications involving a variety of control variables are reported. Since the speeding activity and the population of motorists on the roads vary by time and place, I control for time (using time of day, time of week, month, and holiday dummies), speed limit, and the actual speeding charge code in each specification. Other factors, such as weather and location (county where the citation was issued and whether it was issued on an interstate highway), are also used as controls in some specifications, as are race variables and a dummy for whether the motorist is from a state that borders North Carolina. I control for race in some 
specifications because much of the literature on discrimination deals with enforcement varying by race, with a number of studies finding significant effects. Including race dummies and interaction terms based on those dummies accounts for potentially differential treatment across races so that any such effects do not bias the estimates of the coefficients of interest. I control for whether a motorist is from a bordering state because their speeding outcomes could be different from other out-of-state drivers for a number of reasons. It is possible that they live very close to North Carolina, drive there often, and thus act more like in-state motorists than out-of-state motorists. In other words, the speeding activity of drivers from bordering states may differ from that of drivers from further away. It is also possible that enforcement officers can distinguish plates from these states more easily, conditional on their similarity to North Carolina plates, because these officers see them more often. These officers might have an incentive to treat these drivers more like North Carolina drivers because there is a higher probability that they live nearby. Each of these possibilities could ultimately affect the overspeed outcomes of this group, and thus I control for it.

Table 5 presents the results for the models based on eq. [1]. The coefficients on out-of-state driver show that out-of-state drivers are consistently and very clearly cited at a higher average overspeed. Certainly the order in which the controls were added into the model can make a difference as far as magnitudes and significance. As a practical matter, the most control-heavy specifications (specifications 6 and 7) are likely the most appropriate since cases can be made for ways in which each of these controls could materially affect the dependent variable. The average differential, estimated at 0.91 miles per hour in the most control-heavy specification, is significant at the $1 \%$ level in each specification. Given that $80 \%$ of the observed overspeed values fall between 13 and 23 , this represents roughly $9 \%$ of that relevant range. These results clearly set the expected overspeed baselines for the two groups, and these baselines help provide context for the other results in the paper. The coefficients on the interaction of out-of-state driver and similar plate indicate that drivers with plates resembling North Carolina's are charged at lower average overspeed values, with most of the estimates statistically significant at either the $5 \%$ or $10 \%$ level. The point estimate is -0.16 for the specification with the most controls, so in practical terms the average difference in overspeed outcomes between these groups is less than one-fifth of a mile per hour. While in absolute terms this is not a large number, it does represent close to $18 \%$ of the estimated differential between North Carolina drivers and all out-of-state drivers. This suggests speeding laws are enforced less strictly for out-of-state drivers. 


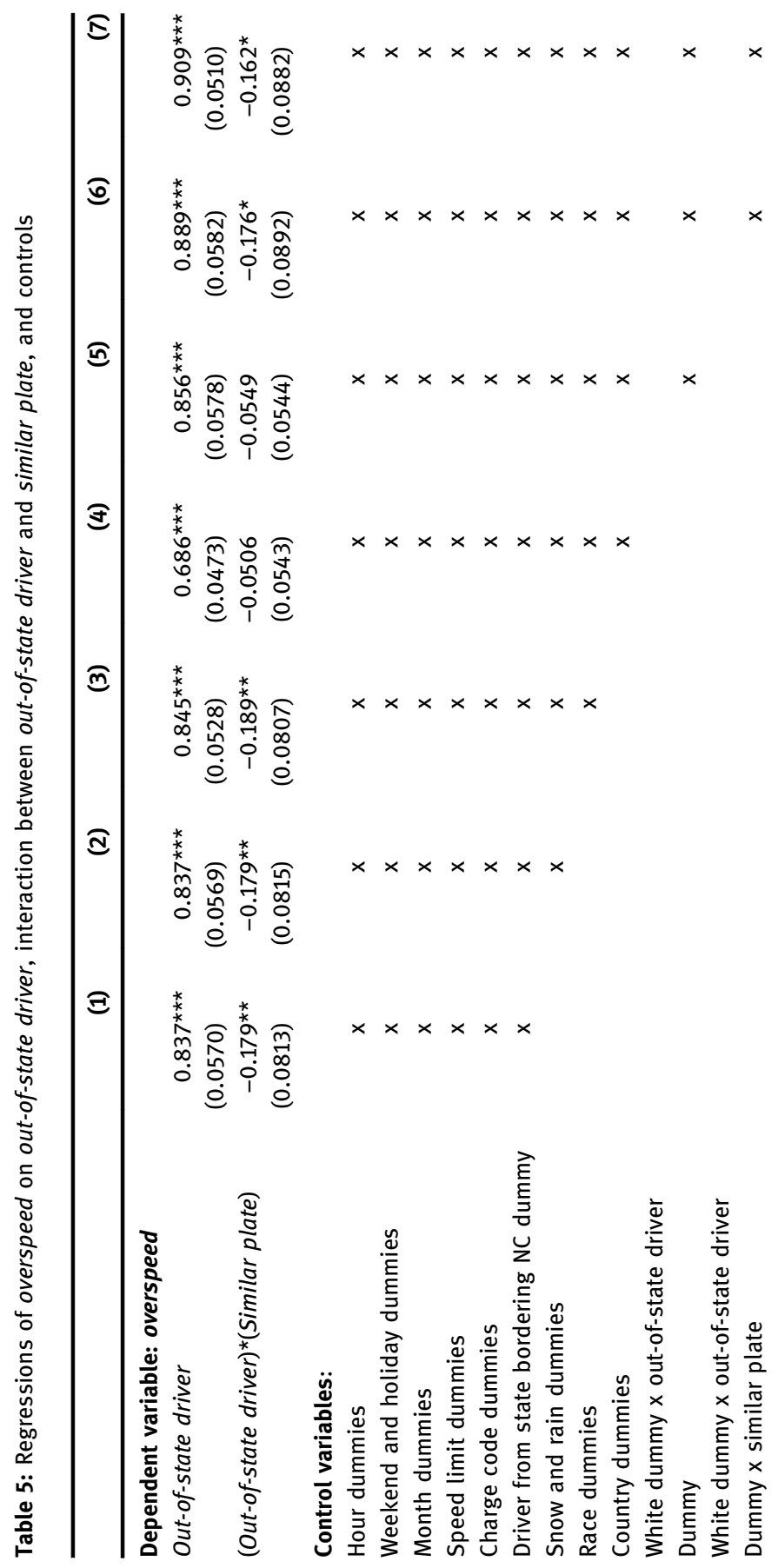




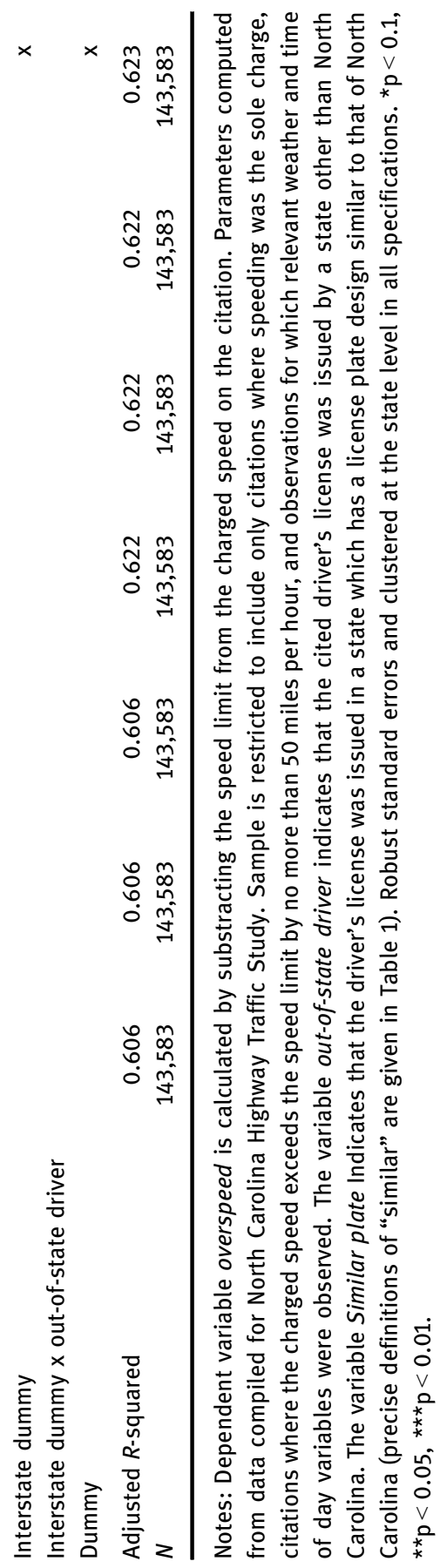




\subsection{Robustness checks and extensions}

I supplement this analysis with several robustness checks and extensions of the specifications presented in Table 5. First, I include a new dummy variable, bordering county, to the regression model shown in eq. [1]. This indicates whether the citation was issued to an out-of-state driver from a state that borders the county in North Carolina where the citation was issued. By construction, this is a subset of the citations issued to drivers from states that border North Carolina, and it represents roughly $16 \%$ of the citations issued to out-of-state drivers. The reason for including this control is similar to the rationale for controlling for bordering states: to account for the possibility that out-of-state drivers who are being cited very close to where they live might be like North Carolina drivers in their behavior or enforcement agents may recognize the fact that these drivers may live nearby.

The second robustness check involves further subdividing the license plates that were classified as not similar to North Carolina's. The key distinction is whether the license plate has a solid, non-white background color, which would be easier to distinguish from a North Carolina license plate. I construct three mutually exclusive categories: similar (similar plate $=1$ ), dissimilar (similar plate $=0$, solid color background $=0$ ), and solid color background (solid color background $=1$ ). I modify eq. [1] by replacing (out-of-state driver)*(similar plate) with two other interaction terms: (out-of-state driver $)^{*}($ dissimilar plate) and (out-of-state driver)*(solid color background). For collinearity reasons, the interaction term involving the third group (similar) is omitted. If troopers are attempting to treat out-of-state drivers differently, I expect drivers from states with a solid background license plate color will receive the most disparate treatment (relative to the out-of-state driver benchmark).

Thirdly, I include specifications with a dummy indicating whether or not the state from which a motorist comes requires a front license plate (front license plate equals 1 if the state requires the front plate and zero otherwise). Because front license plates make it easier for enforcement agents to identify out-of-state drivers as such (since North Carolina has no front plate requirement), I expect this effect to be in the same direction as the effect of having a non-similar plate. The specifications using these new variables are presented in Table 6. In addition to these new variables, I also report some control variables used in the previous analysis that are potentially of interest, especially as it relates to race and interactions involving race.

I find a negative coefficient on bordering county in all specifications, and the estimate is significant at the $1 \%$ level in each specification. Living in a bordering county reduces the average value of overspeed by more than 0.2 of a mile per hour relative to those motorists from bordering states, and it reduces overspeed by more than 0.3 of a mile per hour relative to out-of-state drivers living in non-bordering states (this is so because the estimated coefficient on bordering state is between -0.1 


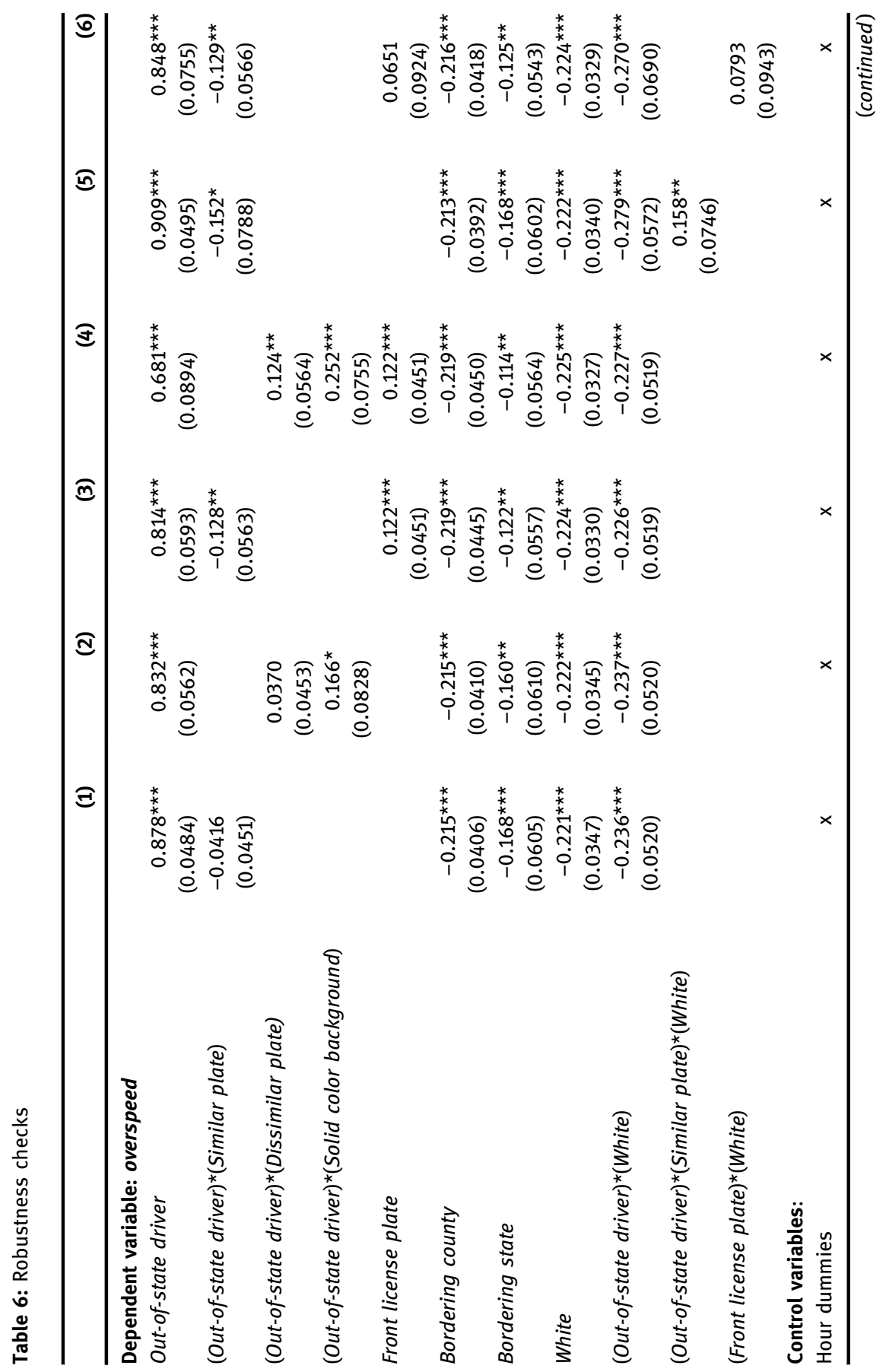




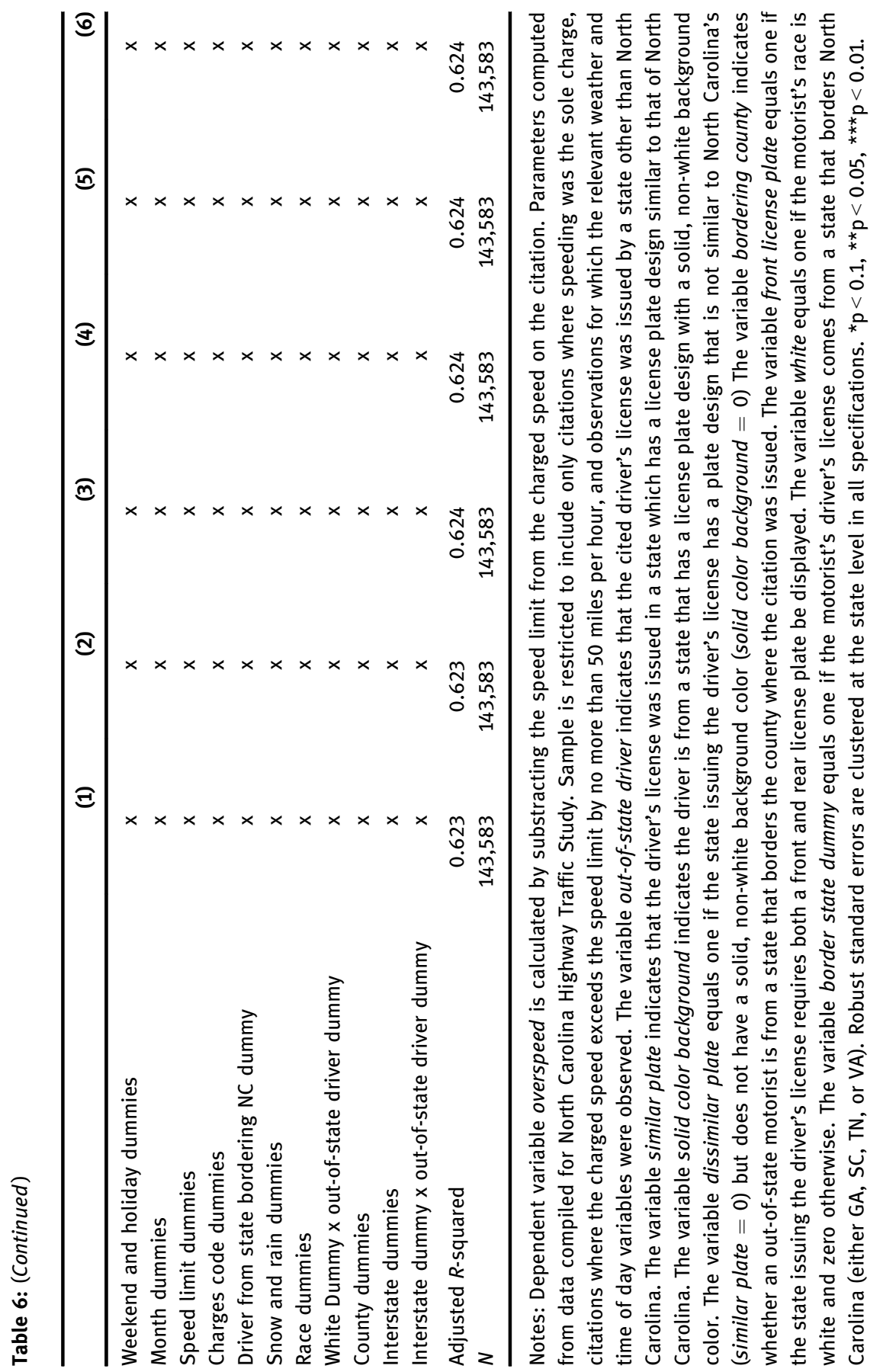


and -0.2 and statistically significant). While small in nominal terms, 0.2 of a mile per hour equates to more than $20 \%$ of the average differential between the overspeed values of a North Carolina driver and an out-of-state driver.

The robustness checks related to other ways of classifying the ease with which out-of-state drivers can be recognized confirm the results of Table 5, where out-ofstate drivers with similar plates were found to face stricter enforcement. The estimates in specification 4 show that having a dissimilar plate (but not one with a solid background color) raises average overspeed by 0.12 miles per hour, having a solid color license plate raises average overspeed by 0.25 miles per hour, and the presence of a front license plate is associated with an additional 0.12 miles per hour increase. Thus, as ease of identification increases, the values of overspeed increase. These respective point estimates correspond to $18 \%, 37 \%$, and $18 \%$ of the baseline differential between in-state and out-of-state drivers calculated in this specification. Furthermore, in the specifications where key explanatory variable is, as in Table 5 (out-of-state driver)*(similar plate), the results are in line with those reported in Table 5 , in terms of both magnitude and significance.

The coefficients on the variables related to race are also of interest, given that discrimination on the basis of race is often the focus of this type of study. Table 6 indicates that white drivers are cited at overspeed values that are 0.22 miles per hour lower on average, and white drivers from states other than North Carolina are cited at values that are a lower by at least an additional 0.23 miles per hour. These values are all statistically significant at the $1 \%$ level, but it is unclear whether this is due to differences in enforcement intensity across races or differences in the underlying speeding activity of these groups. While (front license plate $)^{\star}($ white $)$ is insignificant, the interaction term (out-of-state driver)*(similar plate $)^{\star}($ white $)$ is significant and positive in specification 5 . Indeed, the magnitude is very close to the absolute value of the coefficient on (out-of-state driver) ${ }^{\star}($ similar plate), which is negative. This suggests that the lower average overspeed values for out-of-state drivers with plates similar to North Carolina's are completely due to lower average overspeed values for non-white drivers within this group. While this estimate is not by any means definitive evidence of attempts to vary enforcement intensity across races, it does suggest that race can potentially interact with other factors, and an investigation into racial discrimination in enforcement activities should consider these interactions to the extent possible.

As it relates to the possible theoretical explanations for discrimination, these results point to the deterrence effect (attempting to deter in-state drivers from speeding) as a possible explanation for these disparate treatments of out-of-state drivers. The other proposed explanations for preference-based discrimination (the political economy and opportunity cost explanations for which Makowsky and Stratmann (2009) find support) predict more rigid enforcement for out-of-state 
drivers, and thus do not match up with these empirical findings related to decisions on who to stop (though it is worth noting that these effects might certainly still be present in enforcement decisions made after the stop has been made). The fact that these troopers work for a state agency rather than one that is potentially dependent on the revenue from citations potentially dampens any political economy effect in this context as well. It is important to keep these results in perspective. The magnitudes are not large in practical terms (the differences across groups are less than one mile per hour on average). Still, the statistical significance matters because in some ways, this is a question of whether differences exist at all, and the differences that are found are not small when compared in percentage terms to the overall difference between North Carolina drivers and drivers from other states.

\section{Conclusion}

Consistent enforcement standards of speeding laws would seem to be a simple and reasonable goal. However, agents who enforce these laws face incentives that may lead them to enforce speeding laws more intensely for one group relative to another. The central challenge to measuring whether or not out-ofstate drivers are treated differently comes from the fact that the underlying distribution of speeding activity (for both in-state and out-of-state drivers) is unknown. In order to test whether the treatment differs for this group, I utilize the fact that some drivers are more difficult to identify as out-of-state drivers because their license plates resemble North Carolina drivers' plates. Assuming that the conditional distribution of speeders is uncorrelated with license plate design, one would expect to see no difference in outcomes across motorists groups based on license plate design in the absence of discrimination. Since these outcomes are observed, this framework provides a simple test for discrimination without requiring any assumptions about the underlying distributions of in-state and out-of-state speeding activity. The results of this test show clearly that drivers with license plates that have less pronounced differences from North Carolina plates actually face stricter enforcement of speeding laws than out-ofstate drivers with plates that make them easily distinguishable from North Carolina drivers. The effect holds even in the presence of a wide range of control variables. These results support the notion that Highway Patrol agents attempt to use different criteria for stopping out-of-state drivers than they do for in-state drivers (criteria that would seem to be more favorable from the perspective of out-of-state motorists). The theoretical explanation most in line with these results centers on attempts to deter in-state motorists from speeding due to the larger impact this has on overall speeding activity on roads within the state. 


\section{Appendix 1: License plates classified as similar to North Carolina's}
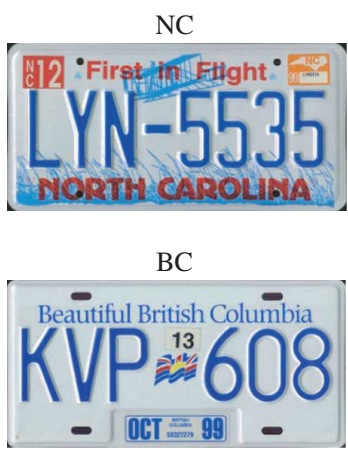

CA

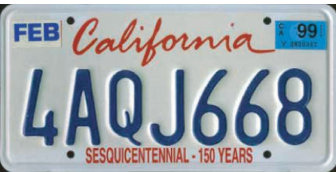

IA

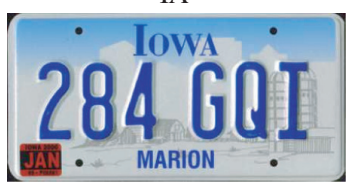

IL

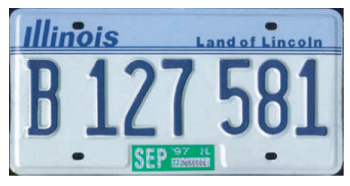

TX
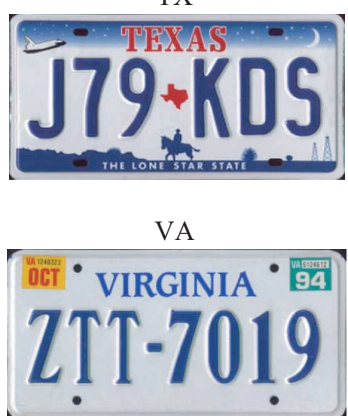

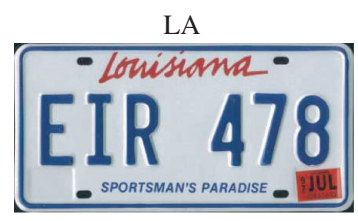

MN

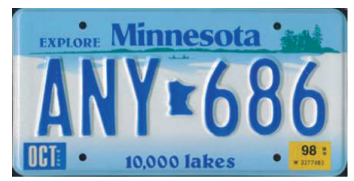

NV

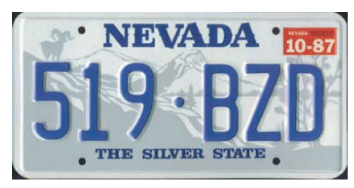

ON

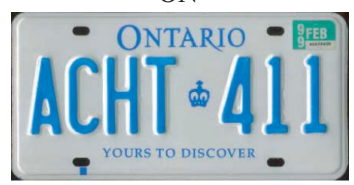

RI

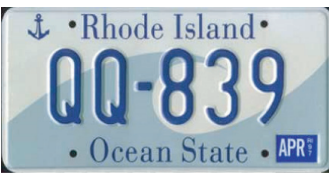

WA

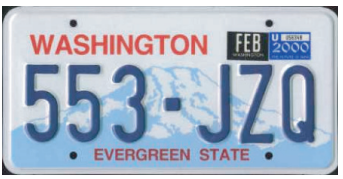




\section{Appendix 2: License plates classified as not similar to North Carolina's}

$\mathrm{AL}$

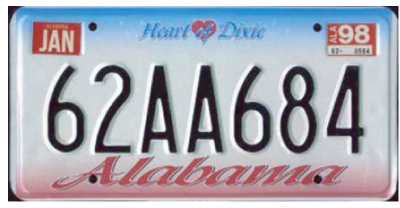

AK

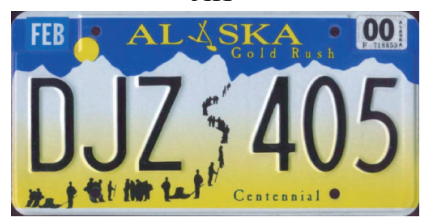

AR

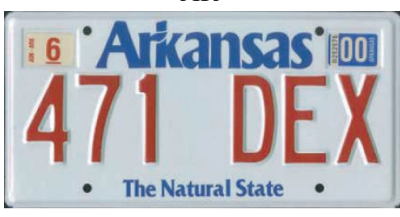

AZ

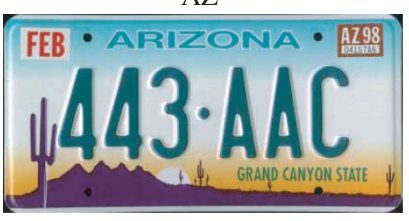

$\mathrm{CO}$

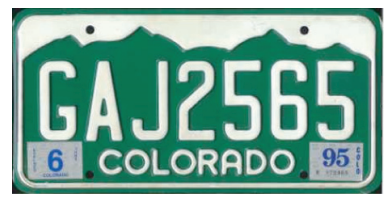

CT

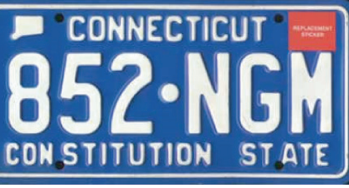

DC

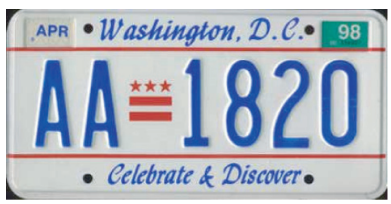

DE

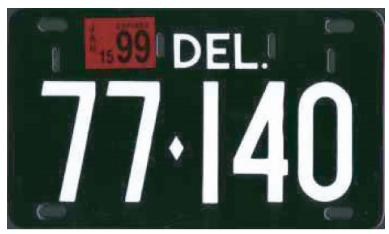

FL

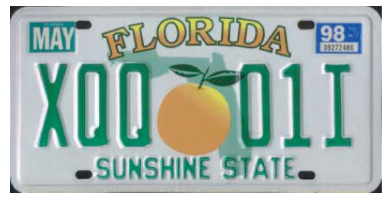

GA

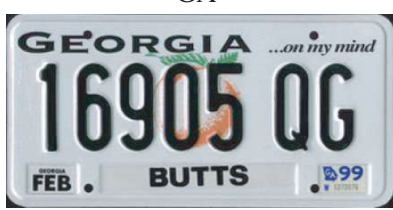


HI

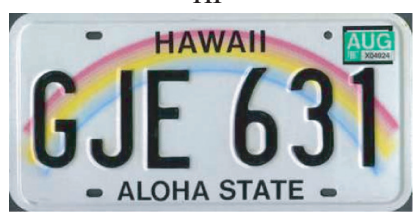

ID
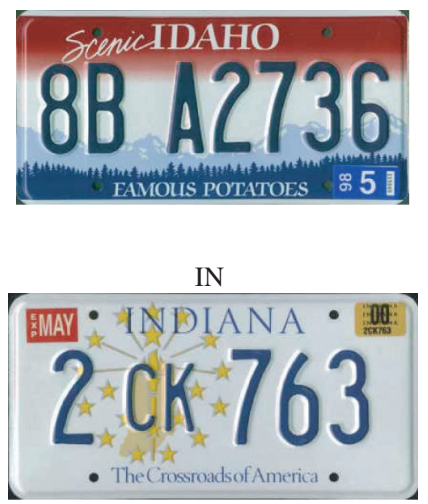

KS

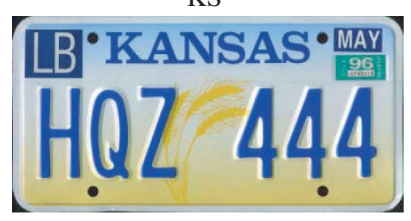

KY

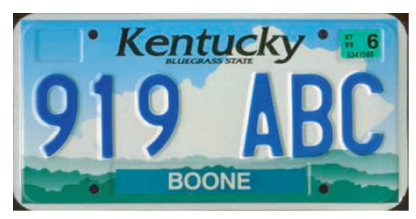

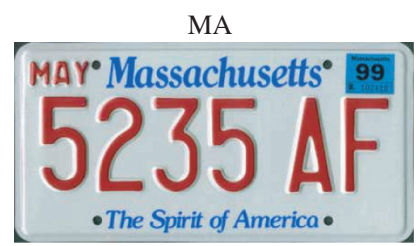

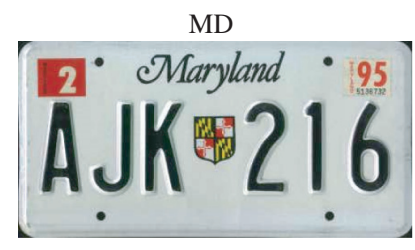

ME

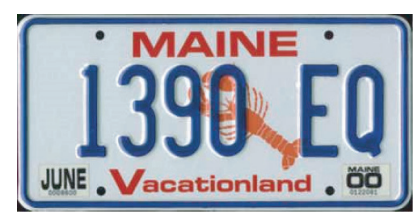

MI

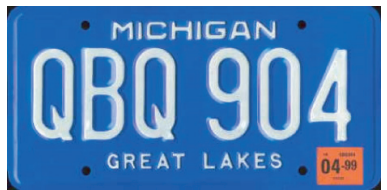

MO

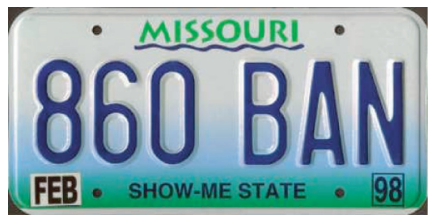


MS
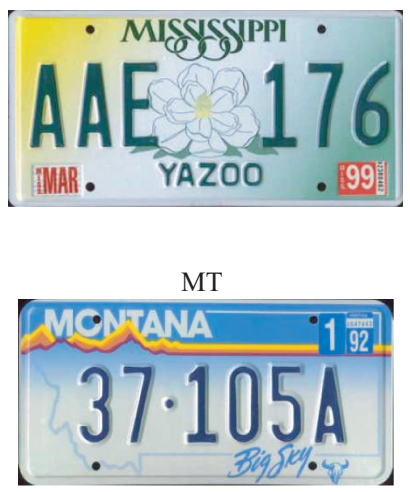

ND

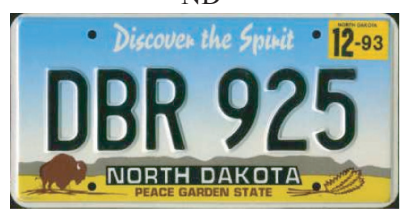

NE

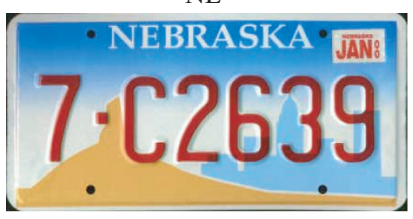

$\mathrm{NH}$

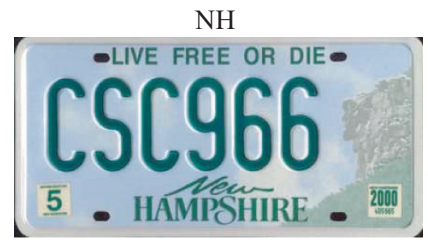

NJ

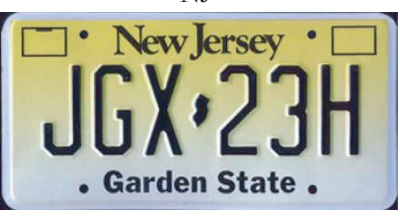

NM

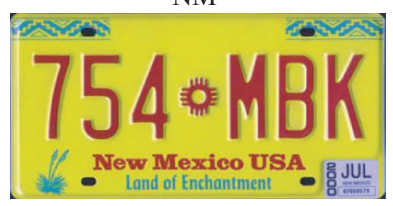

NY

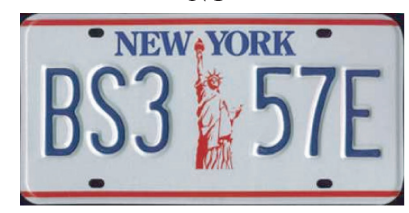

OK
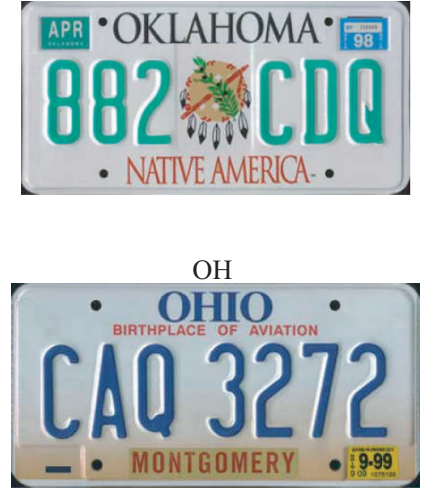

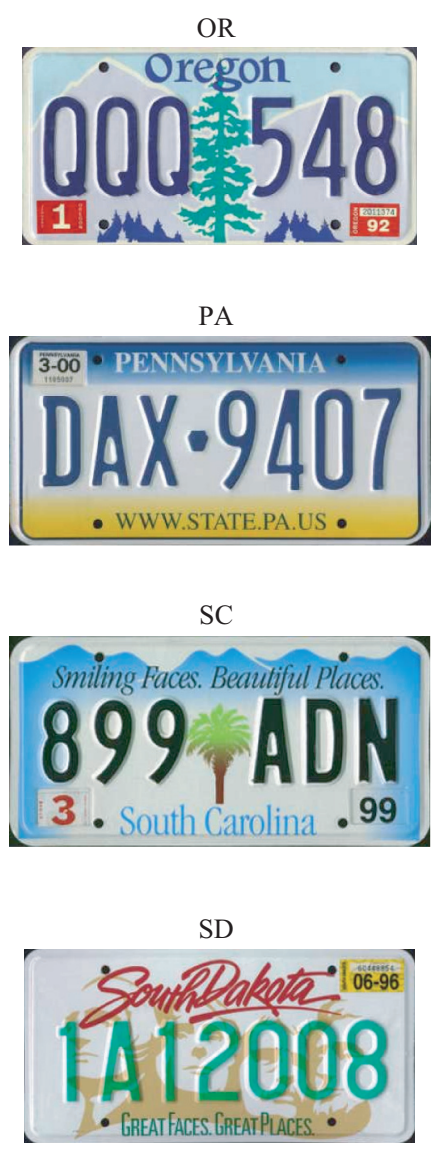

$\mathrm{TN}$

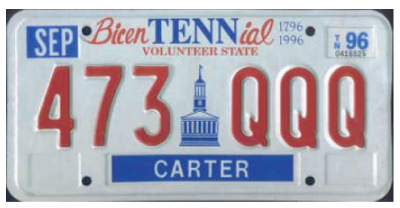

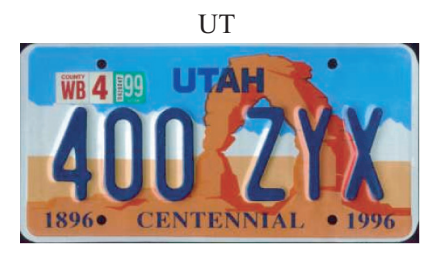
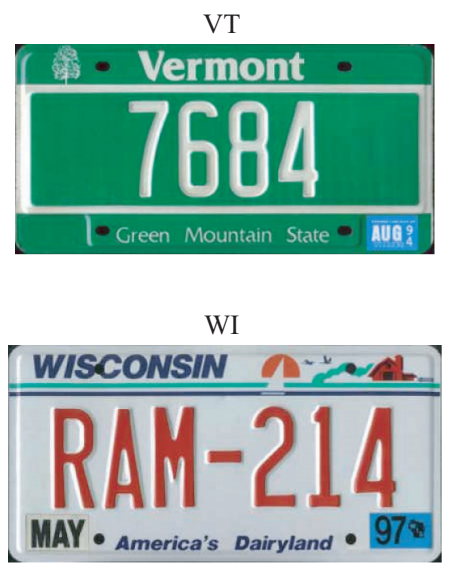

WV

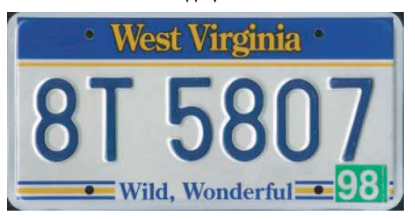

WY

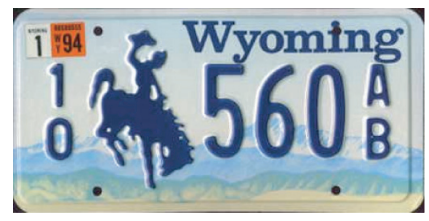




\section{References}

Amaral, B. 2013. "Speed Trap: Records Show Out-of-Town Drivers Targeted by Small N.J. Town's Cops.” NJ.com, October 23. Accessed April 30, 2014. http://www.nj.com/middlesex/index. ssf/2013/10/speed_trap_out-of-town_drivers_targeted_by_small_nj_towns_cops.html

Antonovics, K., and B. G. Knight. 2009. “A New Look at Racial Profiling: Evidence From the Boston Police Department." Review of Economics and Statistics 91:163-77.

Anwar, S., and H. Fang. 2006. "An Alternative Test of Racial Prejudice in Motor Vehicle Searches: Theory and Evidence.” American Economic Review 96:127-51.

Close, B. R., and P. L. Mason. 2007. "Searching for Efficient Enforcement: Officer Characteristics and Racially Biased Policing." Review of Law and Economics 3:263-321.

Garrett, T. A., and G. Wagner. 2009. "Red Ink in the Rearview Mirror: Local Fiscal Conditions and the Issuance of Traffic Tickets." Journal of Law and Economics 52:71-90.

Grogger, J., and G. Ridgeway. 2005. "Testing for Racial Profiling in Traffic Stops from Behind a Veil of Darkness.” Working Paper.

Hernandez-Murillo, R., and J. Knowles. 2004. "Racial Profiling or Racist Policing? Bounds Tests in Aggregate Data." International Economic Review 45:959-89.

Knowles, J., N. Persico, and P. Todd. 2001. "Racial Bias in Motor Vehicle Searches: Theory and Evidence." Journal of Political Economy 109:203-29.

Makowsky, M. D., and T. Stratmann. 2009. "Political Economy at Any Speed: What Determines Traffic Citations?" American Economic Review 99:509-27.

Rood, L. 2013. "Register Investigation: lowa State Patrol Nabs More Drivers from Out of State." The Des Moines Register, October 19. Accessed April 30, 2014. http://archive.desmoinesregister.com/article/20131020/NEWS03/310200043/Register-Investigation-lowa-StatePatrol-nabs-more-drivers-from-out-state

Smith, W. R., D. Tomaskovic-Devey, M. T. Zingraff, H. M. Mason, P. Y. Warren, and C. P. Wright. 2003. "The North Carolina Highway Traffic Study: Final Report to the National Institute of Justice." Department of Justice.

Walden, M., L. Higgins, T. Walden, and S. Hammond. 2012. "Front License Plate Market Research: Comparison of Single versus Dual License Plates.” Texas A\&M Transportation Institute. 